\title{
Case of Cronkhite-Canada Syndrome
}

\author{
Bhageerath Raj D. ${ }^{1} \quad$ B. Ramesh Kumar ${ }^{1} \quad$ Ankit Vijay Agarwal ${ }^{1}$
}

${ }^{1}$ Department of Gastroenterology, Osmania Medical College \& Hospital, Afzalgunj, Hyderabad, Telangana, India

J Digest Endosc

\author{
Address for correspondence Raj D. Bhageerath, MD, DM, \\ Department of Gastroenterology, Osmania General Hospital, \\ Afzal Gunj, Hyderabad 500012, Telangana, India \\ (e-mail: bhageerath_raj@yahoo.com).
}

Retraction Notice Concerning the article "Case of Cronkhite-Canada Syndrome" by Bhageerath Raj D., B. Ramesh Kumar, Ankit Vijay Agarwal there is a quality concern. For this reason The Journal of Digestive Endoscopy gives notice that the paper is retracted by the Editorin-Chief. DOI of the article is DOI: 10.1055/s-0040-1713831. 